OPEN ACCESS

Edited by:

Caoxing Huang,

Nanjing Forestry University, China

Reviewed by:

Shiyan Han,

Northeast Forestry University, China

Dong Lv,

City University of Hong Kong, Hong

Kong, SAR China

${ }^{*}$ Correspondence:

Ting $X u$

xuting@tust.edu.cn

Sun-Eun Choi

oregonin@kangwon.ac.kr

Chuanling SI

sichli@tust.edu.cn

tThese authors have contributed equally to this work and share first authorship

Specialty section:

This article was submitted to Bioprocess Engineering,

a section of the journal

Frontiers in Bioengineering and

Biotechnology

Received: 02 September 2021

Accepted: 07 October 2021

Published: 25 October 2021

Citation:

Zhao $Q, X U T$, Song $X$, Nie $S$, Choi S-E and Si C (2021) Preparation and Application in Water Treatment of

Magnetic Biochar

Front. Bioeng. Biotechnol. 9:769667.

doi: 10.3389/fbioe.2021.769667

\section{Preparation and Application in Water Treatment of Magnetic Biochar}

\author{
Qingshuang Zhao ${ }^{1 \dagger}$, Ting $\mathrm{Xu}^{1,2 * t}$, Xueping Song ${ }^{2}$, Shuangxi $\mathrm{Nie}^{2}$, Sun-Eun $\mathrm{Choi}^{3 *}$ and \\ Chuanling $\mathrm{Si}^{1,2 *}$

\begin{abstract}
${ }^{1}$ Tianjin Key Laboratory of Pulp and Paper, Tianjin University of Science and Technology, Tianjin, China, ${ }^{2}$ Guangxi Key Laboratory of Clean Pulp and Papermaking and Pollution Control, College of Light Industry and Food Engineering, Guangxi University, Nanning, China, ${ }^{3}$ Department of Forest Biomaterials Engineering, College of Forest and Environmental Sciences, Kangwon National University, Chuncheon, South Korea
\end{abstract}

This paper reviews the preparation of magnetic biochar and its application in wastewater treatment, and briefly discusses the adsorption mechanism of biochar to remove pollutants and the modification methods of biochar. Due to the good physical and chemical properties of biochar, including its rough porous structure, it has been widely used to absorb pollutants from water. Magnetic biochar is commonly prepared by combining biochar with magnetic material. The biochar is endowed with the characteristics of the magnetic material, which could effectively solve the problems of difficult recovery and easy loss of adsorbent in water treatment. Magnetic biochar with high carbon content, large specific surface area, magnetic separation, and other excellent properties, has become a hot research topic in recent years. The preparation methods and application properties of magnetic biochar are reviewed. The future research directions of magnetic biochar are put forward to provide directions for further research and application of magnetic biochar materials.

Keywords: magnetic biochar, water treatment, adsorption, magnetic response, adsorption mechanism

\section{INTRODUCTION}

In this era of rapid development of the industry, people's needs are constantly increasing to ensure the conditions of cost control to improve the profits of the industry (Yan et al., 2021; Pei et al., 2020a; Dai et al., 2020; Li X. et al., 2019; Si et al., 2009; Yang et al., 2019; Chen et al., 2020a; Liu et al., 2020a). Agricultural waste has received extensive attention due to its wide application and availability ( $\mathrm{Si}$ et al., 2013; Dai L. et al., 2019; Du et al., 2019; Pei et al., 2020b; Liu et al., 2021c; Liu. et al., 2021e; Ma et al., 2021; Zhang et al., 2021). In these respects, some countries, such as Malaysia, dominated by the department of agriculture, support a most economic turnaround with annual production of more than two million tons of agricultural waste (Yang et al., 2020; Liu et al., 2019; Wang et al., 2019). However, this production is commonly conducted in the open-air, leading to waste being incinerated or dumped in landfill, which can lead to serious environmental problems, such as groundwater pollution or air pollution (Si et al., 2008; Liu et al., 2020b). Materials such as empty fruit bunches, rice husks, and coconut shells were found to be some of the most abundantly available agricultural wastes which contain high amounts of minerals such as silica, magnesium, and potassium along with a high porosity (Laine and Calafat, 1989; Mubarak et al., 2014; Vadivelan et al., 2005; Mubarak et al., 2016; Chen et al., 2020b; Ma et al., 2020; Du et al., 2021).

These agricultural and forestry wastes can be formed into biochar through a common pyrolysis process (Xu, R. et al. 2020b; Cheng, et al. 2020). For example, enhancing the soil fertility for a higher 


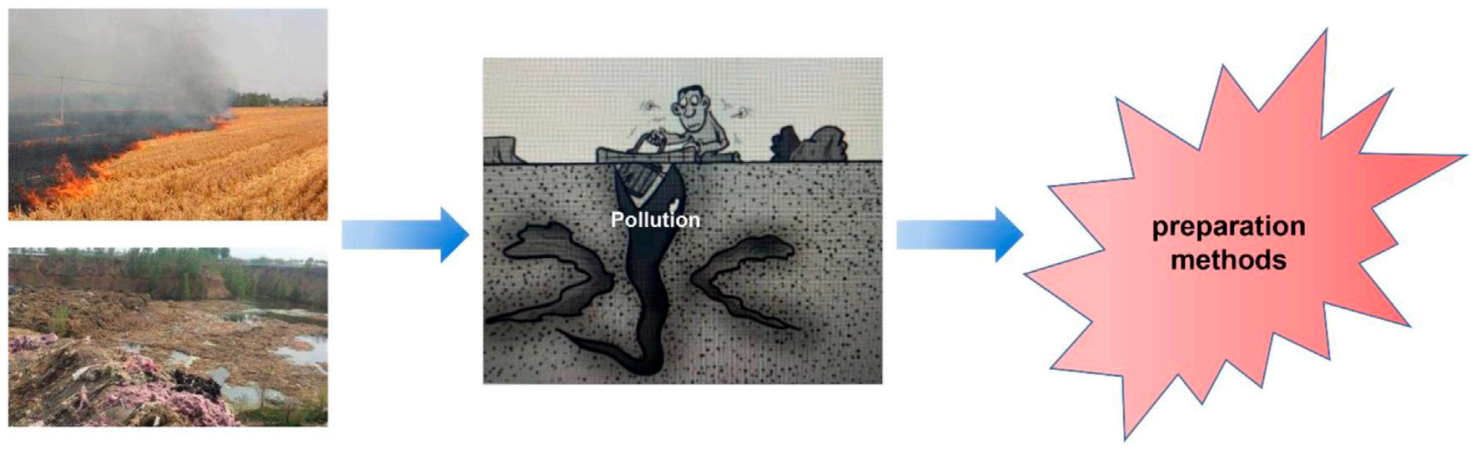

FIGURE 1 | Changes in environmental patterns and solutions to problems.

crop production by increasing the fertilizer's retention time (Liang et al., 2006; Chan et al., 2008), as a dopant to increase the capacitance value of a supercapacitor (Gupta et al., 2015), and as an adsorbent in the removal of various wastewater's contaminants such as lead (Liu and Zhang, 2009), zinc (Chen B. et al., 2011), and natural organic matter (Uchimiya et al., 2010). If the biochar is separated in an aqueous solution, it must be centrifugated (Mukherjee et al., 2011) or activated with a strong base before the biochar can be used in a supercapacitor (Goda et al., 2014; Das et al., 2015). The development of magnetic biochar has overcome this problem, and has been applied in various fields by attaching various metal ions to the surface of biochar to make it magnetic. Magnetic biochar is prepared in the laboratory using conventional heating in an electrical furnace (Zhang et al., 2007; Theydan and Ahmed, 2012; Wang H. et al., 2020), microwave heating in a modified furnace or oven (Wang et al., 2013; Mubarak et al., 2014; Ruthiraan et al., 2015), co-precipitation (Saravanan et al., 2012; Jiang et al., 2015; Yu et al., 2013), and calcination (Gao et al., 2015; Ma et al., 2015). These magnetic biochars adsorb waste water effectively, removing pollutants, such as cadmium (Reddy and Lee, 2014; Mohan et al., 2014), arsenic (Akin et al., 2012; Gao et al., 2015), lead (Wang et al., 2015a; Wang et al., 2015b; Wang et al., 2015), methylene blue (Theydan and Ahmed, 2012; Zhang and Gao, 2013; Mubarak et al., 2014), and phosphate (Chen X. et al., 2011). Besides that, certain selected magnetic biochars showed the excellent capability to be used as electrodes for supercapacitors to increase the capacitance and electrical conductivity value as well (Li and Liu, 2014; Liu et al., 2021a; Xu T. et al., 2021; Du et al., 2022).

This article mainly introduces the preparation method of magnetic biochar and its application in water treatment as well as its wide application in other areas. As shown in Figure 1, people throw away rubbish at will, which causes serious environmental pollution (Lin et al., 2020; Liu et al., 2021b). Water resources have also been severely damaged, but the preparation of magnetic biochar can absorb pollutants in the water. Researchers preparing magnetic biochar need to pay attention to its shortcomings, correction methods, and so on. The preparation of biochar by combining magnetic materials with biochar has become a hot topic for scientists. According to these conditions, the research targets for the future development of magnetic biochar are determined.

\section{PREPARATION METHODS OF MAGNETIC BIOCHAR}

\section{Pyrolysis}

In general, pyrolysis refers to the thermal decomposition of organic matter in the absence of oxygen at temperatures over $400^{\circ} \mathrm{C}$ (Maschio et al., 1992; Thines et al., 2017). Three substances are produced, which consist of a residual solid biochar, a liquid product commonly known as bio-oil, pyrolysis oil, or biocrude, and a non-condensable gas known as syngas, which consists of carbon monoxide $(\mathrm{CO})$, carbon dioxide $\left(\mathrm{CO}_{2}\right)$, hydrogen $\left(\mathrm{H}_{2}\right)$, and methane $\left(\mathrm{CH}_{4}\right)$. The pyrolysis process is generally divided into two stages. In the first stage, heat is transferred to the surface of ions by radiation, from the surface to the interior. During the main pyrolysis and preheating solution, the volatiles and syngas flow through the particles in the void due to the loss of biomass water due to the increase of temperature. The process of heat transfer is a function of time. The second stage of the pyrolysis process begins with the expansion of the solid voids and the conversion of biomass into gas (Blasi, 2008). The expansion of pores provides a site for volatile gases produced during the pyrolysis process. There are three main mechanisms for heat transfer, conduction inside the biomass particle, convection inside the pores of the biomass particle, and the convection and radiation from the surface of the final product.

Accordingly the different operations can be divided into three types: conventional pyrolysis, fast pyrolysis, and flash pyrolysis, as shown in Table 1. The heating rate of traditional pyrolysis is relatively slow which allows for the production of solid, liquid, and gaseous products in compelling portions (Goyal et al., 2008). Traditional pyrolysis can be divided into intermittent pyrolysis and continuous pyrolysis. In the latter stage, few internal repeats occur, such as the breaking of bonds, the appearance of free radicals, the elimination of water, and the formation of hydrogen peroxide (Shafizadeh et al., 1982). The main pyrolysis mainly takes place in the second stage of the high-rate decomposition of 
TABLE 1 | Operating conditions for different types of pyrolysis processes.

\begin{tabular}{|c|c|c|c|}
\hline Parameters & Fast pyrolysis & Flash pyrolysis & Conventional pyrolysis \\
\hline Particle size (mm) & Less than 1 & Less than 0.2 & $5-50$ \\
\hline Residence time(s) & $0.5-1.0$ & Less than 0.5 & $450-550$ \\
\hline Heating rate $(\mathrm{K} / \mathrm{s})$ & 10-200 & Less than 1000 & $0.1-1.0$ \\
\hline
\end{tabular}

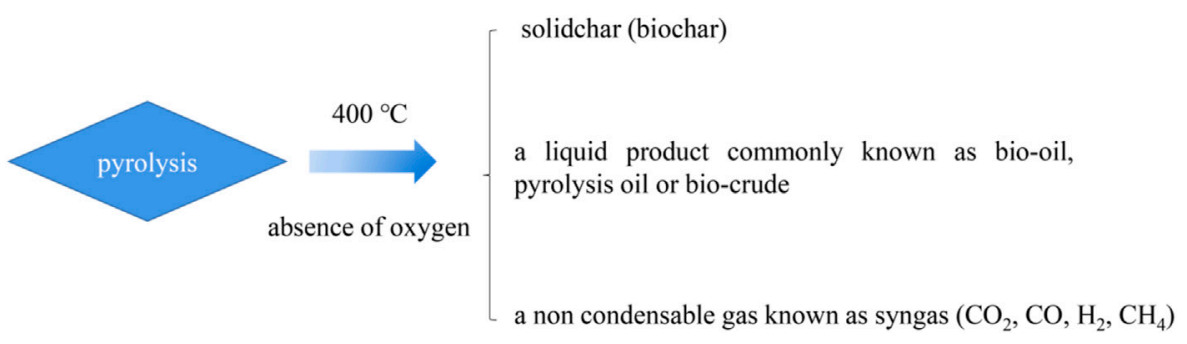

FIGURE 2 | The process of thermal decomposition.

biomass. The third stage is the slow decomposition of the carbon to form a carbon-rich residue known as biochar. The overall yield of conventional pyrolysis would be approximately 35\% biochar, $30 \%$ bio-oil, and 35\% syngas by mass (Laird et al., 2009). Bio-oil mainly exists in the state of steam and aerosol, and cannot be separated from syngas. If this gas is discharged into the environment, it will cause serious environmental pollution. In contrast, when production is mainly concentrated on liquid or gas products, rapid pyrolysis is chosen (Liu et al., 2021d; Liu W. et al., 2021). In the process of rapid pyrolysis, high operating temperature, short contact time, fine particles, and other operating conditions are required if rapid heating is desired (Babu, 2008). The overall yield of fast pyrolysis would be approximately $50-70 \%$ bio-oil, $10-30 \%$ biochar, and $15-20 \%$ syngas by mass (Babu, 2008). Raw materials need to be dried and ground to a size less than $2 \mathrm{~mm}$ before entering the main system of the pyrolysis reactor. However, the temperature of rapid pyrolysis increases rapidly and the particles are sparse. So rapid pyrolysis to produce gaseous products is a good choice (Demirbas et al., 2002). The overall yield of flash pyrolysis would be approximately $60 \%$ biochar and $40 \%$ volatiles by mass. This process consists of a gasifier which allows a small, limited amount of oxygen to enter the reaction chamber which causes partial combustion of biomass, producing 5-15\% char and traces of biooil which are referred to as "tar" (Laird et al., 2009). As for laboratory scale, the pyrolysis process is generally done either through conventional heating or microwave heating. The product decomposition diagram is shown in Figure 2.

\section{Co-Precipitation}

Co-precipitation is the process by which a solute is separated from a solution by means of a carrier, by which the solute is bonded to the solute rather than dissolved in the solution. The solute is called an impurity. This kind of co-precipitation is used in purifying solution and industrial wastewater $(\mathrm{Xu} \mathrm{R}$. et al.,
2021). A solute can be co-precipitated out from a solution through three common methods such as inclusion, occlusion, and surface adsorption (Kolthoff, 1932). Inclusion or also known as the formation of mixed crystals is a process which consists of the incorporation of solute in the crystal lattice of the carrier through a hole in which the regular structure of the carrier remains unchanged. This combination forms a mixed crystal in which the amount depends on the adsorption phenomena during the precipitation process.

Apart from that, during the occlusion process, the solute remains incorporated into the crystal lattice of the carrier, instead of the carrier being completely surrounded by the solute during the formation of the crystal matrix, entrapping the solute from returning to the solution. The surface adsorption process on the other describes how the solute is attached to the surface of the carrier and moves out from the solution only when the crystal matrix forms a large surface area and behaves like a flocculated colloid (Wang P. et al., 2020). In general, the precipitation process is a phenomenon that occurs when a substance reaches a certain saturation, followed by the slow growth of the nucleus as the solute diffuses to the surface of the crystal (Sugimoto, 2003). In addition, some organic ions or polymer surface complexing agents can be added to control the size of the magnetic material (Cai and Wan, 2007). Due to the simplicity of the co-precipitation process and the wide range of operating parameters, the required particle size and characteristics can be obtained for the production of magnetic biochar. Massart et al. (Massart, 1981) were first to perform a controlled preparation of superparamagnetic iron oxide particles utilizing the alkaline precipitation of $\mathrm{FeCl}_{3}$ and $\mathrm{FeCl}_{2}$ which managed to produce spherical magnetite particles with a diameter in the nanometer scale. In addition, another study by Babes et al. (Babes et al., 1999) showed that if the ratio of $\mathrm{Fe}^{2+}$ to $\mathrm{Fe}^{3+}$ increased, the particle size of the magnetic biochar increased, but the yield of magnetic biochar decreased (Wang et al., 2021). 
The extensive growth of this simple yet significant method which controls the particle size of magnetic particles being produced provided space for researchers to perform studies on the production of magnetic biochar based on various biomasses. In this regard, Saravanan et al. (Saravanan et al., 2012) discovered diamond glue, took out a little biological sample, and co-precipitated the ammonia solution $(2: 1)$ with $\mathrm{Fe}^{2+}$ and $\mathrm{Fe}^{3+}$ to produce magnetic iron oxide particles. This magnetic material had good thermal stability compared with the star polymer containing iron oxide particles. Similarly, Mohan et al. (Mohan et al., 2011) prepared magnetic biochar from almond shells by chemical precipitation $\left(\mathrm{FeCl}_{3}\right.$ and $\left.\mathrm{FeSO}_{4}\right)$. The magnetic biochar had a spongy porous structure and the non-magnetic biochar had a porous shape. These remarkable characteristics provide a good source of magnetic biochar with good adsorption properties.

\section{Reductive Co-Deposition}

The reduction co-precipitation process is similar to the coprecipitation process, but the difference is that the transition metal is reduced by a reducing agent such as sodium borohydride or potassium borohydride in the process of binding to the biochar (Wang P. et al., 2020). When the reaction is terminated, the supernatant is removed and the residue is cleaned and dried in a true empty tank to achieve the magnetic biochar. Interestingly, this material is composed of nanoparticles and most of the zerovalent metals, making the magnetic biochar produced highly reductive, and also highly effective at contaminant removal. For example, Zhu et al. (Zhu S. et al., 2018) found that the $\mathrm{Cr}$ adsorption capacity of reduced co-precipitated magnetic biochar was $58.82 \mathrm{mg} / \mathrm{g}$, and that most of the $\mathrm{Cr}$ (VI) was reduced to $\mathrm{Cr}$ (III). Therefore, this method can synthesize magnetic biochar with a better effect and stronger ability to remove pollutants. However, the used reducing agent is harmful and will produce hydrogen during the reduction process, which will pose a certain risk to safety when used on a large scale.

\section{Hydrothermal Carbonization}

Hydrothermal carbonization refers to the heterogeneous reaction of biomass and metal ions, because the reaction temperature $\left(100-300^{\circ} \mathrm{C}\right)$ is relatively low, the reaction pressure is generated by the reaction itself (An et al., 2019). These conditions are milder than the previous conditions, there is no need to add bases or strong reductants, making the reaction easier. For example, Zhang et al. (Ngarmkam et al., 2011; Bastami and Entezari, 2012) successfully synthesized magnetic biochar by this hydrothermal method from iron-containing sludge and sludge at $473^{\circ} \mathrm{C}$, and used the resulting product as a Fenton-like catalyst to completely degrade methylene blue. Similarly, Nethaji et al. (Nethaji et al., 2013) found that magnetic biochar synthesized using this method had a maximum adsorption capacity for $\mathrm{Cr}$ (VI) of up to $142.86 \mathrm{mg} / \mathrm{g}$, which was greater than that of most magnetic biochar prepared by co-precipitation (Baig et al., 2014), reductive co-deposition (Devi and Saroha, 2014), or impregnation pyrolysis (Quan et al., 2014).

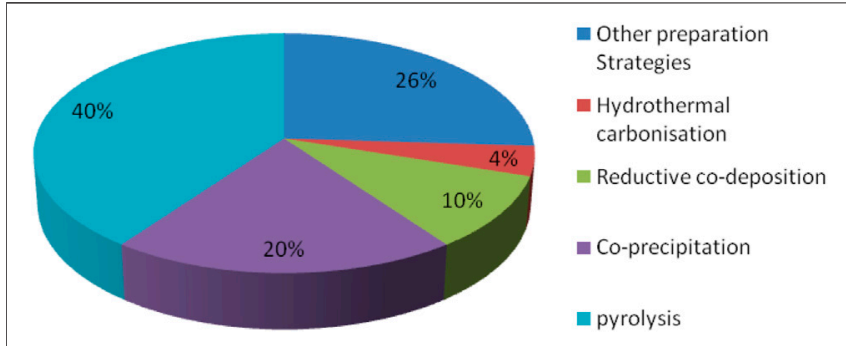

FIGURE 3 | Magnetic biochar synthesis methods.

\section{Other Preparation Strategies}

Recently, other methods for preparing magnetic biochar have also been developed, such as ball milling, in which biochar is mechanically mixed with iron oxides in a solvo-free manner (Shang et al., 2016), direct pyrolysis of biomass/metal salts, and cross-linking of biochar and iron oxides (Mojiri et al., 2019). For example, Shang et al. (Shang et al., 2019) found that the adsorption capacities of magnetic biochar synthesized by ballmilling of biochar and iron oxide for the pharma-ceuticals carbamazepine (CBZ) and tetracycline were $62.7 \mathrm{mg} / \mathrm{g}$ and $94.2 \mathrm{mg} / \mathrm{g}$, respectively. In addition, Dai et al. (Dai S.-j. et al., 2019) demonstrated that the herbicides dichlorophenol and atrazine were very efficiently removed by magnetic biochar synthesized by the molten salt method.

To improve magnetic biochar's ability to heal in the environment more quickly, the researchers treated it with metal or acid or alkali solutions, and also reacted it with different chemical functional groups, in order to improve adsorption selectivity and capacity. A graphical summary of these various methods for the synthesis of magnetic biochar is shown in Figure 3.

Hydrothermal carbonization, reductive co-deposition, coprecipitation, pyrolysis, and other synthetic methods are also used to obtain magnetic biochar. Therefore, the nature of the raw material, the physicochemical properties of the pollutants, and the method operability should be carefully considered when selecting a synthetic approach for magnetic biochar.

\section{APPLICATION OF MAGNETIC BIOCHAR}

Magnetic biochar has the potential to be used in purifying the environment, specifically it can be used as an adsorbent, catalyst, soil remediation agent, etc. The need for clean water is a necessity in every part of the world. The main cause of water pollution may be untreated discharge of heavy metals into nearby water sources by mining, batteries, metal plating, or hazardous wastewater such as organic matter and dyes from the textile industry (Li et al., 2020). Therefore, in order to provide clean water for users, a variety of wastewater treatment technologies are chosen such as ion exchange, membrane filtration, biological treatment, and adsorption to solve this problem. 


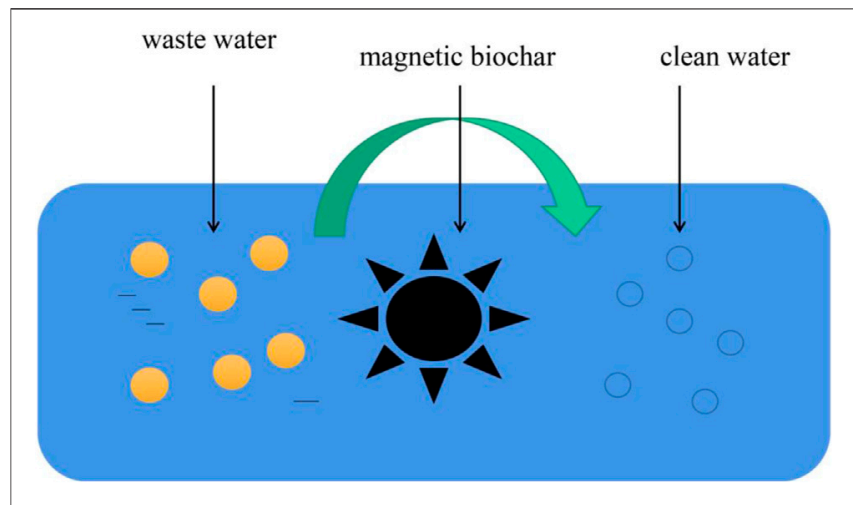

FIGURE 4 | Magnetic biochar adsorbs wastewater pollutants.

\section{Adsorbent}

\section{Adsorption of Heavy Metals}

Heavy metals in the environment also have different states. According to the characteristics of these states, heavy metals are classified as anion or cation type. The adsorption capacity of magnetic biochar for chromium is between $8.35 \mathrm{mg} / \mathrm{g}$ to $220 \mathrm{mg} /$ $\mathrm{g}$, which proved that the adsorption performance of magnetic biochar was greatly affected by raw materials (Ifthikar et al., 2017). The mechanism by which $\mathrm{Cr}$ (VI) is removed by magnetic biochar involves electrostatic adsorption, reduction, ion exchange, complexation with functional groups, and coprecipitation. The adsorption capacity of magnetic biochar is different with the difference of valence, being $1.305-45.8 \mathrm{mg} / \mathrm{g}$ and $1.630-10.07 \mathrm{mg} / \mathrm{g}$. For the removal of As, the adsorption mechanism of magnetic biochar is mainly electrostatic adsorption and functional group complexation, among which iron oxide plays a key role (Lu et al., 2004).

The cationic heavy metal pollutants removed by magnetic biochar are mainly $\mathrm{Cd}$ (II), $\mathrm{Pb}$ (II), $\mathrm{Cu}$ (II), $\mathrm{Ni}$ (II), Sb (II), Sn (II), and $\mathrm{Hg}$ (II), and the efficiency of their removal is influenced by their different physical and chemical properties (Sozeri et al., 2013). The removal mechanism of metal cations by magnetic biochar is as follows: 1) electrostatic adsorption; 2) ion exchange; 3) surface complexation; 4) $\pi-\pi$ interaction; 5) internal spherical complexation; 6) hydrogen bonding; and 7) co-deposition. Magnetic biochar is also used for the removal of multiple heavy metals. In systems polluted with multiple heavy metal species, the various heavy metals compete for adsorption sites, which affects the overall adsorption behavior of the magnetic biochar.

\section{Adsorption of Nuclear Waste Pollutants}

In recent years, magnetic biochar has become more widely used to remove pollutants from nuclear waste $\mathrm{U}$ (VI) and $\mathrm{Eu}$ (III) (Hu et al., 2018). For example, Zhu et al. (Zhu Y. et al., 2018) found that the maximum adsorption capacity of magnetic biochar to $\mathrm{Eu}$ was $105.53 \mathrm{mg} / \mathrm{g}$, and concluded that the mechanism of magnetic biochar's removal of pollutants was surface and inner sphere complexation. At the same time, Li M. et al.'s (Li M. et al., 2019) research results showed that the maximum adsorption capacity of magnetic biochar for $\mathrm{U}$ is $52.63 \mathrm{mg} / \mathrm{g}$, and its pollutant removal mechanism is inner sphere complexation. It can be seen from these that the pollutants from nuclear waste can be effectively removed by magnetic biochar, which is a process of enrichment, when the complex charge of these pollutants in magnetic biochar is relatively high. Therefore, what to do with magnetic biochar, which contains pollutants that absorb nuclear waste, also remains a challenge. The schematic diagram of purifying wastewater with magnetic biochar is shown in Figure 4.

\section{Adsorption of Organic Pollutants}

Magnetic biochar showed a good adsorption performance for organic pollutants, and the removal of organic pollutants by magnetic biochar was mainly antibiotics, organic dyes, pesticides, and organochlorine compounds (Kumar et al., 2020). Meng et al. (Meng et al., 2015) summarized the adsorption effect of magnetic biochar on antibiotics. According to these data, tetracycline is the most common removal, with adsorption loads ranging from $33.1 \mathrm{mg} / \mathrm{g}$ to $297.61 \mathrm{mg} / \mathrm{g}$, followed by methanoxazole, with adsorption loads ranging from 5.19 to $212.8 \mathrm{mg} / \mathrm{g}$. It mainly summarized the mechanism of antibiotic removal by magnetic biochar and these involve hydrogen bonding, $\pi-\pi$ interactions, pore-filling effects, electrostatic adsorption, and hydrophobic interactions.

The organic dyes that are adsorbed by magnetic biochar are rhodamine $\mathrm{B}$, methylene blue, malachite green, acid orange 7 (AO-7), and orange-G. The saturated adsorption capacity of magnetic biochar for these dyes ranged from 31.25 to $388.65 \mathrm{mg} / \mathrm{g}$, while the mechanism of adsorption of dyes by magnetic biochar was less discussed.

At the same time, magnetic biochar can also remove other organic pollutants, such as pesticides, phenol, organochlorine, and hormones. The adsorption capacity varies from 3.46 to $169.7 \mathrm{mg} / \mathrm{g}$. The removal mechanisms of these substances by magnetic biochar involve hydrogen bonding, $\pi-\pi$ interactions, pore-filling effects, electrostatic adsorption, hydrophobic interactions, and reductive dehalogenation (Mun et al., 2013).

\section{Adsorption of Inorganic Anion Pollutants}

Magnetic biochar can also be used to remove inorganic pollutants such as phosphate, nitrate, fluoride, etc. (Cai et al., 2017; Xu et al.,

FIGURE 5 | The removal of antibiotics by magnetic biochar. $\begin{aligned} & \text { Applaction of } \\ & \text { Adsorption of heavy metals } \\ & \text { Adsorption of nuclear waste pollutants } \\ & \text { Adsorption of organic pollutants } \\ & \text { Adsorption of inorganic anion pollutants }\end{aligned}$


2020a). Compared with other pollutants, nitrate has been studied the most, and the adsorption capacity of magnetic biochar is between 1.26 and $474.26 \mathrm{mg} / \mathrm{g}$ (Li et al., 2017). The modified magnetic biochar has a good adsorption capacity of phosphate. In addition, the magnetic biochar has a good adsorption capacity of nitrate and fluoride, and the adsorption capacity is about 9 to $15 \mathrm{mg} / \mathrm{g}$. The results show that co-precipitation, electrostatic adsorption, surface complexation, inner sphere complexation, and ligand exchange are present. Finally, due to the ability of magnetic biochar to adsorb a large number of nutrients, it could be used as a slow-release fertilizer to improve the composition of soil elements and soil fertility (Figure 5).

\section{Catalytic Degradation of Organic Pollutants}

Magnetic biochar has also been used as a catalyst for hydrogen peroxide, producing a highly reactive oxidizing substance that is used to degrade organic matter. For example, Chen et al. (Chen et al., 2018) found that the antibiotic ofloxacin could be efficiently degraded by magnetic biochar and persulfate. Meanwhile, Zhang et al. (Zhang et al., 2018) demonstrated that methylene blue can be completely removed by magnetic biochar coupled with hydrogen peroxide. Because different organisms have different physical and chemical properties, some organisms cannot remove organic pollutants at all by using female organisms. So, we can take advantage of the function of the female organism, the catalytic property, which is to produce hydroxyl radicals inside of the organism in time, to produce strong oxidizing radicals that attack organic pollutants freely, in a way that maximizes the function of the magnetic biochar. If it is difficult to remove organic pollutants by using magnetic biological carbon, its catalytic properties can be considered to achieve efficient degradation of organic pollutants.

\section{Other Applications}

In addition to the above functions, magnetic biochar can also be used as a photocatalytic carrier, for example, Li M. et al. (Li M. et al., 2019) prepared the $\mathrm{Fe}_{3} \mathrm{O}_{4} / \mathrm{BiOBr} / \mathrm{BC}$ photocatalyst using magnetic biochar as a carrier and found that its removal efficiency of propranolol was nearly 95\%. Similarly, magnetic biochar can effectively recover precious metals by adsorption and enrichment. For example, Zhang et al. (Zhang et al., 2019) found that the adsorption capacity of magnetic biochar for silver ions was $818.4 \mathrm{mg} / \mathrm{g}$.

It is very interesting that Qin et al. (Qin et al., 2017) used magnetic organisms in the process of anaerobic digestion, but as an additive, they found that a small amount of magnetic biochar promoted the production of methane on anaerobic digestion, and finally found methanogenic bacteria that produced methane, which facilitated recycling. And finally, female organisms could not just be used for environmental remediation, but also for energy storage (Hu et al., 2019; Lu et al., 2019). For example, Thines et al. (Thines et al., 2017) found that the density capacitance and energy could be increased when magnetic biological carbon was used as an electric conductor. Meanwhile, Jiang et al.'s (Jiang et al., 2019) research results showed that hydrogen could be effectively recovered in the process of removing nitrophenol. Although magnetic biochar has a good adsorption effect, due to the release of a lot of heat in the preparation process, the yield is low, and the adsorption may not be complete, difficult to recover, and may cause secondary pollution to the environment. The large-scale application of magnetic biochar is limited.

\section{CONCLUSION AND PROSPECTS}

The remarkable properties of magnetic biochar and its special role in related industrial production have attracted great attention. In fact, demand for magnetic biochar has been growing over the past few years. However, this extensive demand is faced with the innovation and breakthrough of the preparation technology, and the solution of the current key technology and restriction links is conducive to the further large-scale production of magnetic biological carbon. In fact, the successful experience gives people a profound enlightenment, one to optimize the choice of production materials. As mentioned earlier, a large amount of agricultural waste can be used to produce magnetic biological carbon, and the expansion potential is huge. Second, the production process should be selected reasonably. For the production of magnetic biochar from agricultural wastes, new processes should be established based on actual conditions. In terms of selection criteria, not only the characterization elements of raw materials should be considered, but also important factors such as moisture content, ash content, carbon content, and surface area should be fully considered. These elements have a direct effect on the morphology and properties of the produced magnetic biochar, and will play a crucial role.

Therefore, the production of magnetic biochar from agricultural waste must be thoroughly understood and analyzed before it is developed into magnetic biochar. In addition, agricultural wastes must be pre-treated with particular care to avoid the spread of harmful pollutants from these wastes and their spread into the surrounding environment through water or air sources. At the same time, it is necessary to fully consider the transportation cost of batch scale and the cost of pretreatment when producing magnetic biochar from various agricultural wastes. It is very important to choose an open site for the treatment of agricultural waste. Through the combustion treatment, the prevention and control of gas pollution should be fully considered. The negative impact on the surrounding environment can be effectively reduced during the production of magnetic biochar through the application of new processes. Magnetic biochar can be produced by new environmental protection technology and strive to become an environmentally friendly product. On the other hand, after the successful development of magnetic biochar, the problems of marketing must be fully considered. The production of magnetic biochar from agricultural waste and its application in wastewater treatment or the electrolysis industry need a process of application and effect approval. It is necessary to organize effective verification tests, especially to carry out cooperation between science and enterprise, and to carry out series promotion and application in combination with production practice. If 
magnetic biochar products are successful in specific applications, more enterprises will invest in this environmental protection industry, which will further promote the development of the magnetic biochar industry for agricultural waste development. At the same time, the application of magnetic biochar can be expanded by coating other carbon materials such as carbon nanotubes or graphene or polymers to improve its performance and expand its application in other industries.

In fact, the wide application of biochar in different industries requires continuous improvement, and research and development of new magnetic biochar production is very necessary. It is undoubtedly a new attempt to produce magnetic biochar with specific properties by improving the production method and improving the adsorption characteristics of biological carbon. Three main production methods have been identified as successful in producing effective forms of magnetic biochar with high porosity, magnetic strength, and significant morphology, which can perform well in related applications. It has been proved that magnetic biochar produced from various types of agricultural wastes has a high adsorption capacity to lead, chromium, copper, tetracycline, methylene blue, and crystal violet. In addition, magnetic biochar loaded with different metal salt ions also has high capacity, high density, and high efficiency. Therefore, the production of magnetic biochar by different production methods can open up a new recycling method for the full utilization of

\section{REFERENCES}

Akin, I., Arslan, G., Tor, A., Ersoz, M., and Cengeloglu, Y. (2012). Arsenic(V) Removal from Underground Water by Magnetic Nanoparticles Synthesized from Waste Red Mud. J. Hazard. Mater. 235-236, 62-68. doi:10.1016/j.jhazmat2012.06.02410.1016/ j.jhazmat.2012.06.024

An, L., Si, C., Wang, G., Sui, W., and Tao, Z. (2019). Enhancing the Solubility and Antioxidant Activity of High-Molecular-Weight Lignin by Moderate Depolymerization via In Situ Ethanol/acid Catalysis. Ind. Crops Prod. 128, 177-185. doi:10.1016/j.indcrop.2018.11.009

Babes, L., Denizot., B., Tanguy, G., LeJeune, J. J., and Jallet, P. (1999). Synthesis of Iron Oxide Nanoparticles Used as MRI Contrast Agents: a Parametric Study. J. Colloid Interf. Sci. 212, 474-482. doi:10.1006/jcis.1998.6053

Babu, B. V. (2008). Biomass Pyrolysis: a State-Of-The-Art Review. Biofuels, Bioprod. Bioref. 2, 393-414. doi:10.1002/bbb.92

Baig, S. A., Zhu, J., Muhammad, N., Sheng, T., and Xu, X. (2014). Effect of Synthesis Methods on Magnetic Kans Grass Biochar for Enhanced As(III, V) Adsorption from Aqueous Solutions. Biomass and Bioenergy 71, 299-310. doi:10.1016/ j.jenvman.2017.03.08510.1016/j.biombioe.2014.09.027

Bastami, T. R., and Entezari, M. H. (2012). Activated Carbon from Carrot Dross Combined with Magnetite Nanoparticles for the Efficient Removal of P-Nitrophenol from Aqueous Solution. Chem. Eng. J. 210, 510-519. doi:10.1016/j.cej.2012.08.011

Cai, R., Wang, X., Ji, X., Peng, B., Tan, C., and Huang, X. (2017). Phosphate Reclaim from Simulated and Real Eutrophic Water by Magnetic Biochar Derived from Water Hyacinth. J. Environ. Manage. 187, 212-219. doi:10.1016/ j.jenvman.2016.11.047

Cai, W., and Wan, J. (2007). Facile Synthesis of Superparamagnetic Magnetite Nanoparticles in Liquid Polyols. J. Colloid Interf. Sci. 305, 366-370. doi:10.1016/ j.jcis.2006.10.023

Chan, K. Y., Van Zwieten, L., Meszaros, I., Downie, A., and Joseph, S. (2007). Agronomic Values of Greenwaste Biochar as a Soil Amendment. Soil Res. 45, 629-634. doi:10.1071/SR07109 abundant agricultural wastes, and its application prospect is very broad.

\section{AUTHOR CONTRIBUTIONS}

Writing original draft: QZ and TX; Supervision: XS and SN; Review and editing: CS, S-EC.

\section{FUNDING}

This work was supported by the National Natural Science Foundation of China (32071720). This work was also supported by 2021 Universities leading lab-specific start-ups through the National Research Foundation of Korea (NRF) grant funded by the Korea government (MSIT), the "Beyond Research Innovation and Development for Good Enterprises +" Project, supported by the Ministry of Education (MOE), and partially supported by the Technology Development Program (S3030198) funded by the Ministry of SMEs and Startups (MSS, Korea) to S-EC. In addition, the grants (Nos. 2021KF02, 2021KF32) from the Foundation of Guangxi Key Laboratory of Clean Pulp and Papermaking and Pollution Control, College of Light Industry and Food Engineering, Guangxi University were much appreciated.

Chen, B., Chen, Z., and Lv, S. (2011a). A Novel Magnetic Biochar Efficiently Sorbs Organic Pollutants and Phosphate. Bioresour. Technol. 102, 716-723. doi:10.1016/j.biortech.2010.08.067

Chen, L., Yang, S., Zuo, X., Huang, Y., Cai, T., and Ding, D. (2018). Biochar Modification Significantly Promotes the Activity of $\mathrm{Co} 3 \mathrm{O} 4$ towards Heterogeneous Activation of Peroxymonosulfate. Chem. Eng. J. 354, 856-865. doi:10.1016/j.cej.2018.08.098

Chen, S., Wang, G., Sui, W., Parvez, A. M., Dai, L., and Si, C. (2020b). Novel LigninBased Phenolic Nanosphere Supported Palladium Nanoparticles with Highly Efficient Catalytic Performance and Good Reusability. Ind. Crops Prod. 145, 112164. doi:10.1016/j.indcrop.2020.112164

Chen, S., Wang, G., Sui, W., Parvez, A. M., and Si, C. (2020a). Synthesis of LigninFunctionalized Phenolic Nanosphere Supported Ag Nanoparticles with Excellent Dispersion Stability and Catalytic Performance. Green. Chem. 22, 2879-2888. doi:10.1039/c9gc04311j

Chen, X., Chen, G., Chen, L., Chen, Y., Lehmann, J., McBride, M. B., et al. (2011b). Adsorption of Copper and Zinc by Biochars Produced from Pyrolysis of Hardwood and Corn Straw in Aqueous Solution. Bioresour. Technol. 102, 8877-8884. doi:10.1016/j.biortech.2011.0607810.1016/j.biortech.2011.06.078

Cheng, Z., Meng, J., and Wang, X. (2020). Preparation of Wood-Based Filter Loaded with Ag Nanoparticles and Its Catalytic Degradation Performance on Organic Dye. J. Forest. Eng. 50 (6), 94-98. doi:10.13360/j.issn.20961359.202004005

Dai, L., Ma, M., Xu, J., Si, C., Wang, X., Liu, Z., et al. (2020). All-Lignin-Based Hydrogel with Fast pH-Stimuli Responsiveness for Mechanical Switching and Actuation. Chem. Mater. 32, 4324-4330. doi:10.1021/ acs.chemmater.0c01198

Dai, L., Zhu, W., Lu, J., Kong, F., Si, C., and Ni, Y. (2019a). A Lignin-Containing Cellulose Hydrogel for Lignin Fractionation. Green. Chem. 21, 5222-5230. doi:10.1039/c9gc01975h

Dai, S.-j., Zhao, Y.-c., Niu, D.-j., Li, Q., and Chen, Y. (2019b). Preparation and Reactivation of Magnetic Biochar by Molten Salt Method: Relevant Performance for Chlorine-Containing Pesticides Abatement. J. Air Waste Manage. Assoc. 69, 58-70. doi:10.1080/10962247.2018.1510441 
Das, O., Sarmah, A. K., and Bhattacharyya, D. (2015). A Novel Approach in Organic Waste Utilization through Biochar Addition in wood/polypropylene Composites. Waste Manage. 38, 132-140. doi:10.1016/j.wasman.2015.01.015

Demirbas, A., and Arin, G. (2002). An Overview of Biomass Pyrolysis. Energy Sources 24, 471-482. doi:10.1080/00908310252889979

Devi, P., and Saroha, A. K. (2014). Synthesis of the Magnetic Biochar Composites for Use as an Adsorbent for the Removal of Pentachlorophenol from the Effluent. Bioresour. Technol. 169, 525-531. doi:10.1016/j.biortech.2014.07.062

Diblasi, C. (2008). Modeling Chemical and Physical Processes of wood and Biomass Pyrolysis. Prog. Energ. Combustion Sci. 34, 47-90. doi:10.1016/ j.pecs.2006.12.001

Du, H., Liu, W., Zhang, M., Si, C., Zhang, X., and Li, B. (2019). Cellulose Nanocrystals and Cellulose Nanofibrils Based Hydrogels for Biomedical Applications. Carbohydr. Polym. 209, 130-144. doi:10.1016/j.carbpol.2019.01.020

Du, H., Parit, M., Liu, K., Zhang, M., Jiang, Z., Huang, T.-S., et al. (2021). Multifunctional Cellulose Nanopaper with superior Water-Resistant, Conductive, and Antibacterial Properties Functionalized with Chitosan and Polypyrrole. ACS Appl. Mater. Inter. 13 (27), 32115-32125. doi:10.1021/ acsami. 1 c06647

Du, H., Zhang, M., Liu, K., Parit, M., Jiang, Z., Zhang, X., et al. (2022). Conductive PEDOT:PSS/cellulose Nanofibril Paper Electrodes for Flexible Supercapacitors with superior Areal Capacitance and Cycling Stability. Chem. Eng. J. 428, 131994. doi:10.1016/j.cej.2021.12199410.1016/ j.cej.2021.131994

Gao, H., Lv, S., Dou, J., Kong, M., Dai, D., Si, C., et al. (2015). The Efficient Adsorption Removal of $\mathrm{Cr}(\mathrm{VI})$ by Using $\mathrm{Fe}_{3} \mathrm{O}_{4}$ Nanoparticles Hybridized with Carbonaceous Materials. RSC Adv. 5, 60033-60040. doi:10.1039/C5RA10236G

Goda, K., Sreekala, M. S., Malhotra, S. K., Joseph, K., and Thomas, S. (2014). Advances in Polymer Composites: Biocomposites-State of the Art, New Challenges, and Opportunities. Polym. Composites, 1-10. doi:10.1002/ 9783527674220.ch1

Goyal, H. B., Seal, D., and Saxena, R. C. (2008). Bio-fuels from Thermochemical Conversion of Renewable Resources: a Review. Renew. Sustain. Energ. Rev. 12, 504-517. doi:10.1016/j.rser.2006.07.014

Gupta, R. K., Dubey, M., Kharel, P., Gu, Z., and Fan, Q. H. (2015). Biochar Activated by Oxygen Plasma for Supercapacitors. J. Power Sourc. 274, 1300-1305. doi:10.1016/j.jpowsour.2014.10.169

Harikishore Kumar Reddy, D., and Lee, S.-M. (2014). Magnetic Biochar Composite: Facile Synthesis, Characterization, and Application for Heavy Metal Removal. Colloids Surf. A: Physicochemical Eng. Aspects 454, 96-103. doi:10.1016/j.colsurfa.2014.03.105

Hu, L., Du, H., Liu, C., Zhang, Y., Yu, G., Zhang, X., et al. (2019). Comparative Evaluation of the Efficient Conversion of Corn Husk Filament and Corn Husk Powder to Valuable Materials via a Sustainable and Clean Biorefinery Process. ACS Sustain. Chem. Eng. 7, 1327-1336. doi:10.1021/acssuschemeng.8b05017

$\mathrm{Hu}$, Q., Zhu, Y., Hu, B., Lu, S., and Sheng, G. (2018). Mechanistic Insights into Sequestration of U(VI) toward Magnetic Biochar: Batch, XPS and EXAFS Techniques. J. Environ. Sci. 70, 217-225. doi:10.1016/j.jes.2018.01.013

Ifthikar, J., Wang, J., Wang, Q., Wang, T., Wang, H., Khan, A., et al. (2017). Highly Efficient lead Distribution by Magnetic Sewage Sludge Biochar: Sorption Mechanisms and Bench Applications. Bioresour. Technol. 238, 399-406. doi:10.1016/j.biortech.2017.03.133

Jiang, S.-F., Xi, K.-F., Yang, J., and Jiang, H. (2019). Biochar-supported Magnetic noble Metallic Nanoparticles for the Fast Recovery of Excessive Reductant during Pollutant Reduction. Chemosphere 227, 63-71. doi:10.1016/ j.chemosphere.2019.04.044

Jiang, Y., Gong, J.-L., Zeng, G.-M., Ou, X.-M., Chang, Y.-N., Deng, C.-H., et al. (2016). Magnetic Chitosan-Graphene Oxide Composite for Anti-microbial and Dye Removal Applications. Int. J. Biol. Macromolecules 82, 702-710. doi:10.1016/ j.ijbiomac.2015.11.021

Kolthoff, I. M. (1932). Theory of Coprecipitation. The Formation and Properties of Crystalline Precipitates. J. Phys. Chem. 36, 860-881. doi:10.0121/j150333a00810.1021/j150333a008

Kumar, A., Sharma, G., Naushad, M., Al-Muhtaseb, A. a. H., García-Peñas, A., Mola, G. T., et al. (2020). Bio-inspired and Biomaterials-Based Hybrid Photocatalysts for Environmental Detoxification: A Review. Chem. Eng. J. 382, 122937. doi:10.1016/j.cej.2019.122937
Laine, J., Calafat, A., and labady, M. (1989). Preparation and Characterization of Activated Carbons from Coconut Shell Impregnated with Phosphoric Acid. Carbon 27, 191-195. doi:10.1016/0008-6223(89)90123-1

Laird, D. A., Brown, R. C., Amonette, J. E., and Lehmann, J. (2009). Review of the Pyrolysis Platform for Coproducing Bio-Oil and Biochar. Biofuels, Bioprod. Bioref. 3, 547-562. doi:10.1002/bbb.169

Li, H., Mahyoub, S. A. A., Liao, W., Xia, S., Zhao, H., Guo, M., et al. (2017). Effect of Pyrolysis Temperature on Characteristics and Aromatic Contaminants Adsorption Behavior of Magnetic Biochar Derived from Pyrolysis Oil Distillation Residue. Bioresour. Technol. 223, 20-26. doi:10.1016/ j.biortech.2016.10.033

Li, M., Liu, H., Chen, T., Dong, C., and Sun, Y. (2019a). Synthesis of Magnetic Biochar Composites for Enhanced Uranium(VI) Adsorption. Sci. Total Environ. 651, 1020-1028. doi:10.1016/j.scitotenv.2018.09.259

Li, X., Lu, X., Nie, S., Liang, M., Yu, Z., Duan, B., et al. (2020). Efficient Catalytic Production of Biomass-Derived Levulinic Acid over Phosphotungstic Acid in Deep Eutectic Solvent. Ind. Crops Prod. 145, 112154. doi:10.1016/ j.indcrop.2020.112154

Li, X., Xu, R., Yang, J., Nie, S., Liu, D., Liu, Y., et al. (2019b). Production of 5hydroxymethylfurfural and Levulinic Acid from Lignocellulosic Biomass and Catalytic Upgradation. Ind. Crops Prod. 130, 184-197. doi:10.1016/ j.indcrop.2018.12.082

Li, Y., and Liu, X. (2014). Activated carbon/ZnO Composites Prepared Using Hydrochars as Intermediate and Their Electrochemical Performance in Supercapacitor. Mater. Chem. Phys. 148, 380-386. doi:10.1016/ j.matchemphys.2014.07.058

Liang, B., Lehmann, J., Solomon, D., Kinyangi, J., Grossman, J., O’neill, B., et al. (2006). Black Carbon Increases Cation Exchange Capacity in Soils. Soil Sci. Soc. Am. J. 70, 1719-1730. doi:10.2136/sssaj2005.0383

Lin, W., Xing, S., Jin, Y., Lu, X., Huang, C., and Yong, Q. (2020). Insight into Understanding the Performance of Deep Eutectic Solvent Pretreatment on Improving Enzymatic Digestibility of Bamboo Residues. Bioresour. Technol. 306, 123163. doi:10.1016/j.biortech.2020.123163

Liu, H., Du, H., Zheng, T., Liu, K., Ji, X., Xu, T., et al. (2021a). Cellulose Based Composite Foams and Aerogels for Advanced Energy Storage Devices. Chem. Eng. J. 426, 130817. doi:10.1016/j.cej.2021.130817

Liu, H., Xu, T., Liu, K., Zhang, M., Liu, W., Li, H., et al. (2021b). Lignin-based Electrodes for Energy Storage Application. Ind. Crops Prod. 165, 113425. doi:10.1016/j.indcrop.2021.113425

Liu, K., Du, H., Zheng, T., Liu, H., Zhang, M., Zhang, R., et al. (2021c). Recent Advances in Cellulose and its Derivatives for Oilfield Applications. Carbohydr. Polym. 259, 117740. doi:10.1016/j.carbpol.2021.117740

Liu, K., Du, H., Zheng, T., Liu, W., Zhang, M., Liu, H., et al. (2021d). Lignincontaining Cellulose Nanomaterials: Preparation and Applications. Green. Chem. doi:10.1039/d1gc02841c

Liu, S., Du, H., Liu, K., Ma, M.-G., Kwon, Y.-E., Si, C., et al. (2021e). Flexible and Porous $\mathrm{Co}_{3} \mathrm{O}_{4}$-Carbon Nanofibers as Binder-free Electrodes for Supercapacitors. Adv. Compos. Hybrid. Mater. 4. doi:10.1007/s42114-02100344-8

Liu, W., Du, H., Liu, H., Xie, H., Xu, T., Zhao, X., et al. (2020b). Highly Efficient and Sustainable Preparation of Carboxylic and Thermostable Cellulose Nanocrystals via $\mathrm{FeCl}_{3}$-Catalyzed Innocuous Citric Acid Hydrolysis. ACS Sustain. Chem. Eng. 8, 16691-16700. doi:10.1021/acssuschemeng.0c06561

Liu, W., Du, H., Liu, K., Liu, H., Xie, H., Si, C., et al. (2021f). Sustainable Preparation of Cellulose Nanofibrils via Choline Chloride-Citric Acid Deep Eutectic Solvent Pretreatment Combined with High-Pressure Homogenization. Carbohydr. Polym. 267, 118220. doi:10.1016/j.carbpol.2021.118220

Liu, W., Du, H., Zhang, M., Liu, K., Liu, H., Xie, H., et al. (2020a). Bacterial Cellulose-Based Composite Scaffolds for Biomedical Applications: A Review. ACS Sustain. Chem. Eng. 8, 7536-7562. doi:10.1021/ acssuschemeng.0c00125

Liu, W., Si, C., Du, H., Zhang, M., Zhang, X., Xie, H., et al. (2019). Advance in Preparation of Nanocellulose-Based Hydrogels and Their Biomedical Applications. J. Forest. Eng. 4 (5), 11-19. doi:10.13360/j.issn.20961359.2019.05.002

Liu, Z., and Zhang, F.-S. (2009). Removal of lead from Water Using Biochars Prepared from Hydrothermal Liquefaction of Biomass. J. Hazard. Mater. 167, 933-939. doi:10.1016/j.jhazmat.2009.0108510.1016/j.jhazmat.2009.01.085 
Lu, A.-H., Schmidt, W., Matoussevitch, N., Bönnemann, H., Spliethoff, B., Tesche, B., et al. (2004). Nanoengineering of a Magnetically Separable Hydrogenation Catalyst. Angew. Chem. 116, 4403-4406. doi:10.1002/chin.20044323110.1002/ ange.200454222

Lu, J., Zhu, W., Dai, L., Si, C., Si, C., and Ni, Y. (2019). Fabrication of Thermo- and pH-Sensitive Cellulose Nanofibrils-Reinforced Hydrogel with Biomass Nanoparticles. Carbohydr. Polym. 215, 289-295. doi:10.1016/ j.carbpol.2019.03.100

Ma, C., Ma, M. G., Si, C., Ji, X. X., and Wan, P. (202120095). Flexible MXene-Based Composites for Wearable Devices. Adv. Funct. Mater. 31, 2009524. doi:10.1002/ adfm.202009524

Ma, C., Yuan, Q., Du, H., Ma, M.-G., Si, C., and Wan, P. (2020). Multiresponsive MXene $\left(\mathrm{Ti}_{3} \mathrm{C}_{2} \mathrm{Tx}\right)$-Decorated Textiles for Wearable Thermal Management and Human Motion Monitoring. ACS Appl. Mater. Inter. 12, 34226-34234. doi:10.1021/acsami.0c10750

Ma, H., Li, J.-B., Liu, W.-W., Miao, M., Cheng, B.-J., and Zhu, S.-W. (2015). Novel Synthesis of a Versatile Magnetic Adsorbent Derived from Corncob for Dye Removal. Bioresour. Technol. 190, 13-20. doi:10.1016/j.biortech.2015.04.048

Maschio, G., Koufopanos, C., and Lucchesi, A. (1992). Pyrolysis, a Promising Route for Biomass Utilization. Bioresour. Technol. 42, 219-231. doi:10.1016/09608524(92)90025-s

Massart, R. (1981). Preparation of Aqueous Magnetic Liquids in Alkaline and Acidic media. IEEE Trans. Magn. 17, 1247-1248. doi:10.1109/ tmag.1981.1061188

Meng, Y., Chen, D., Sun, Y., Jiao, D., Zeng, D., and Liu, Z. (2015). Adsorption of $\mathrm{Cu}^{2+}$ Ions Using Chitosan-Modified Magnetic Mn Ferrite Nanoparticles Synthesized by Microwave-Assisted Hydrothermal Method. Appl. Surf. Sci. 324, 745-750. doi:10.1016/j.apsusc.2014.11.028

Mojiri, A., Andasht Kazeroon, R., and Gholami, A. (2019). Cross-Linked Magnetic Chitosan/Activated Biochar for Removal of Emerging Micropollutants from Water: Optimization by the Artificial Neural Network. Water 11 (3), 551. doi:10.3390/w11030551

Mohan, D., Kumar, H., Sarswat, A., Alexandre-Franco, M., and Pittman, C. U. (2014). Cadmium and Lead Remediation Using Magnetic Oak Wood and Oak Bark Fast Pyrolysis Biochars. Chem. Eng. J. 236, 513-528. doi:10.1016/ j.cej.2013.09.057

Mohan, D., Sarswat, A., Singh, V. K., Alexandre-Franco, M., and Pittman, C. U. (2011). Development of Magnetic Activated Carbon from almond Shells for Trinitrophenol Removal from Water. Chem. Eng. J. 172, 1111-1125. doi:10.1016/j.cej.2011.06.054

Mubarak, N. M., Kundu, A., Sahu, J. N., Abdullah, E. C., and Jayakumar, N. S. (2014). Synthesis of palm Oil Empty Fruit bunch Magnetic Pyrolytic Char Impregnating with $\mathrm{FeCl}_{3}$ by Microwave Heating Technique. Biomass and Bioenergy 61, 265-275. doi:10.1016/j.biombioe.2013.12.021

Mubarak, N. M., Sahu, J. N., Abdullah, E. C., and Jayakumar, N. S. (2016). Plam Oil Empty Fruit bunch Based Magnetic Biochar Composite Comparison for Synthesis by Microwave-Assisted and Conventional Heating. J. Anal. Appl. Pyrolysis 120, 521-528. doi:10.1016/j.jaap.2016.06.026

Mukherjee, A., Zimmerman, A. R., and Harris, W. (2011). Surface Chemistry Variations Among a Series of Laboratory-Produced Biochars. Geoderma 163, 247-255. doi:10.1016/j.geoderma.2011.04.021

Mun, S. P., Cai, Z., and Zhang, J. (2013). Magnetic Separation of CarbonEncapsulated Fe Nanoparticles from Thermally-Treated wood Char. Mater. Lett. 96, 5-7. doi:10.1016/j.matlet.2013.01.006

Nethaji, S., Sivasamy, A., and Mandal, A. B. (2013). Preparation and Characterization of Corn Cob Activated Carbon Coated with Nano-Sized Magnetite Particles for the Removal of $\mathrm{Cr}(\mathrm{VI})$. Bioresour. Technol. 134, 94-100. doi:10.1016/j.biortech.2013.02.012

Ngarmkam, W., Sirisathitkul, C., and Phakakornkule, C. (2011). Magnetic Composite Prepared from Palm Shelf-based Carbon and Application for Recovery of Residual Oil from POME. J. Environ. Manage 92, 472-479. doi:10.1016/j.jenvman.2010.08.031

Pei, W., Chen, Z. S., Chan, H. Y. E., Zheng, L., Liang, C., and Huang, C. (2020a). Isolation and Identification of a Novel Anti-protein Aggregation Activity of Lignin-Carbohydrate Complex from Chionanthus Retusus Leaves. Front. Bioeng. Biotechnol. 8, 573991. doi:10.3389/fbioe.2020.573991

Pei, W., Shang, W., Liang, C., Jiang, X., Jiang, X., Huang, C., et al. (2020b). Using Lignin as the Precursor to Synthesize $\mathrm{Fe}_{3} \mathrm{O}_{4} @$ lignin Composite for Preparing
Electromagnetic Wave Absorbing Lignin-Phenol-Formaldehyde Adhesive. Ind. Crops Prod. 154, 112638. doi:10.1016/j.indcrop.2020.112638

Qin, Y., Wang, H., Li, X., Cheng, J. J., and Wu, W. (2017). Improving Methane Yield from Organic Fraction of Municipal Solid Waste (OFMSW) with Magnetic rice-straw Biochar. Bioresour. Technol. 245, 1058-1066. doi:10.1016/j.biortech.2017.09.047

Quan, G., Sun, W., and Yan, J. (2014). Nanoscale Zerovalent Iron Supported on Biochar: Characterization and Reactivity for Degradation of Acid Orange 7 from Aqueous Solution. Water, Air, and Soil Pollution 225, 2195. doi:10.1007/s11270-014-2195-3

Ruthiraan, M., Mubarak, N. M., Thines, R. K., Abdullah, E. C., Sahu, J. N., Jayakumar, N. S., et al. (2015). Comparative Kinetic Study of Functionalized Carbon Nanotubes and Magnetic Biochar for Removal of $\mathrm{Cd}^{2+}$ Ions from Wastewater. Korean J. Chem. Eng. 32, 446-457. doi:10.1007/s11814-014-0260-7

Saravanan, P., Vinod, V. T. P., Sreedhar, B., and Sashidhar, R. B. (2012). Gum Kondagogu Modified Magnetic Nano-Adsorbent: An Efficient Protocol for Removal of Various Toxic Metal Ions. Mater. Sci. Eng. C 32, 581-586. doi:10.1016/j.msec.2011.12.015

Shang, J., Pi, J., Zong, M., Wang, Y., Li, W., and Liao, Q. (2016). Chromium Removal Using Magnetic Biochar Derived from Herb-Residue. J. Taiwan Inst. Chem. Eng. 68, 289-294. doi:10.1016/j.jtice.2016.09.012

Shafizadeh, F. (1982). Introduction to Pyrolysis of Biomass. J. Anal. Appl. Pyrolysis 3, 283-305. doi:10.1016/0165-2370(82)80017-X

Si, C.-L., Kim, J.-K., Bae, Y.-S., and Li, S.-M. (2009). Phenolic Compounds in the Leaves of Populus Ussuriensisand Their Antioxidant Activities. Planta Med. 75, 1165-1167. doi:10.1055/s-0029-1185476

Si, C.-L., Liu, Z., Kim, J.-K., and Bae, Y.-S. (2008). Structure Elucidation of Phenylethanoid Glycosides from Paulownia Tomentosa Steud. Var. Tomentosa wood. Holzforschung 62, 197-200. doi:10.1515/hf.2008.047

Si, C.-L., Shen, T., Jiang, Y.-Y., Wu, L., Yu, G.-J., Ren, X.-D., et al. (2013). Antioxidant Properties and Neuroprotective Effects of Isocampneoside II on Hydrogen Peroxide-Induced Oxidative Injury in PC12 Cells. Food Chem. Toxicol. 59, 145-152. doi:10.1016/j.fct.2013.05.051

Sozeri, H., Kurtan, U., Topkaya, R., Baykal, A., and Toprak, M. S. (2013). Polyaniline (PANI) $-\mathrm{Co}_{0.5} \mathrm{Mn}_{0.5} \mathrm{Fe}_{2} \mathrm{O}_{4} \quad$ Nanocomposite: Synthesis, Characterization and Magnetic Properties Evaluation. Ceramics Int. 39, 5137-5143. doi:10.1016/j.ceramint.2012.12.009

Sugimoto, T. (2003). Formation of Monodispersed Nano- and Micro-particles Controlled in Size, Shape, and Internal Structure. Chem. Eng. Technol. 26, 313-321. doi:10.1002/ceat.200390048

Theydan, S. K., and Ahmed, M. J. (2012). Adsorption of Methylene Blue onto Biomass-Based Activated Carbon by $\mathrm{FeCl}_{3}$ Activation: Equilibrium, Kinetics, and Thermodynamic Studies. J. Anal. Appl. Pyrolysis 97, 116-122. doi:10.1016/ j.jaap.2012.05.008

Thines, K. R., Abdullah, E. C., Mubarak, N. M., and Ruthiraan, M. (2017). Insitu Polymerization of Magnetic Biochar - Polypyrrole Composite: A Novel Application in Supercapacitor. Biomass and Bioenergy 98, 95-111. doi:10.1016/j.biombioe.2017.01.019

Thines, K. R., Abdullah, E. C., Ruthiraan, M., Mubarak, N. M., and Tripathi, M. (2016). A New Route of Magnetic Biochar Based Polyaniline Composites for Supercapacitor Electrode Materials. J. Anal. Appl. Pyrolysis 121, 240-257. doi:10.1016/j.jaap.2016.08.004

Uchimiya, M., Lima, I. M., Klasson, K. T., and Wartelle, L. H. (2010). Contaminant Immobilization and Nutrient Release by Biochar Soil Amendment: Roles of Natural Organic Matter. Chemosphere 80, 935-940. doi:10.1016/ j.chemosphere.2010.05.020

Vadivelan, V., and Kumar, K. V. (2005). Equilibrium, Kinetics, Mechanism, and Process Design for the Sorption of Methylene Blue onto Rice Husk. J. Colloid Interface Sci. 286, 90-100. doi:10.1016/j.jcis.2005.01.007

Wang, H., Du, H., Liu, K., Liu, H., Xu, T., Zhang, S., et al. (2021). Sustainable Preparation of Bifunctional Cellulose Nanocrystals via Mixed $\mathrm{H}_{2} \mathrm{SO}_{4} /$ formic Acid Hydrolysis. Carbohydr. Polym. 266, 118107. doi:10.1016/ j.carbpol.2021.118107

Wang, H., Xie, H., Du, H., Wang, X., Liu, W., Duan, Y., et al. (2020a). Highly Efficient Preparation of Functional and Thermostable Cellulose Nanocrystals via $\mathrm{H}_{2} \mathrm{SO}_{4}$ Intensified Acetic Acid Hydrolysis. Carbohydr. Polym. 239, 116233. doi:10.1016/j.carbpol.2020.116233 
Wang, M. C., Sheng, G. D., and Qiu, Y. P. (2015). A Novel Manganese-Oxide/ biochar Composite for Efficient Removal of Lead(II) from Aqueous Solutions. Int. J. Environ. Sci. Technol. 12, 1719-1726. doi:10.1007/s13762-014-0538-7

Wang, P., Yin, B., Dong, H., Zhang, Y., Zhang, Y., Chen, R., et al. (2020b). Coupling Biocompatible Au Nanoclusters and Cellulose Nanofibrils to Prepare the Antibacterial Nanocomposite Films. Front. Bioeng. Biotechnol. 8, 986. doi:10.3389/fbioe.2020.00986

Wang, S., Gao, B., Li, Y., Mosa, A., Zimmerman, A. R., Ma, L. Q., et al. (2015a). Manganese Oxide-Modified Biochars: Preparation, Characterization, and Sorption of Arsenate and lead. Bioresour. Technol. 181, 13-17. doi:10.1016/ j.biortech.2015.01.044

Wang, S., Gao, B., Zimmerman, A. R., Li, Y., Ma, L., Harris, W. G., et al. (2015b). Removal of Arsenic by Magnetic Biochar Prepared from Pinewood and Natural Hematite. Bioresour. Technol. 175, 391-395. doi:10.1016/j.biortech.2014.10.104

Wang, W., Wang, X., Wang, X., Yang, L., Wu, Z., Xia, S., et al. (2013). Cr(VI) Removal from Aqueous Solution with Bamboo Charcoal Chemically Modified by Iron and Cobalt with the Assistance of Microwave. J. Environ. Sci. 25, 1726-1735. doi:10.1016/S1001-0742(12)60247-2

Wang, X., Li, X., Ge, W., and Yang, Y. (2019). Progress in Biomass-Derived Carbon Materials/MnO2 Composite and Its Application in Supercapacitors. J. Forest. Eng. 4 (6), 1-10. doi:10.13360/j.issn.2096-1359.2019.06.001

Xu, J., Li, C., Dai, L., Xu, C., Zhong, Y., Yu, F., et al. (2020a). Biomass Fractionation and Lignin Fractionation towards Lignin Valorization. ChemSusChem 13, 4284-4295. doi:10.1002/cssc.202001491

Xu, R., Du, H., Liu, C., Liu, H., Wu, M., Zhang, X., et al. (2021a). An Efficient and Magnetic Adsorbent Prepared in a Dry Process with Enzymatic Hydrolysis Residues for Wastewater Treatment. J. Clean. Prod. 313, 127834. doi:10.1016/ j.jclepro.2021.127834

$\mathrm{Xu}, \mathrm{R} ., \mathrm{Si}, \mathrm{C}$., Kong, F., and Li, X. (2020b). Synthesis of $\gamma$-valerolactone and Its Application in Biomass Conversion. Forest. Eng. 5 (2), 20-28. doi:10.13360/ j.issn.2096-1359.201904004

Xu, T., Du, H., Liu, H., Liu, W., Zhang, X., Si, C., et al. (2021b). Advanced Nanocellulose-Based Composites for Flexible Functional Energy Storage Devices. Adv. Mater., 2101368. doi:10.1002/adma.202101368

Yan, B., Chen, Z. S., Hu, Y., and Yong, Q. (2021). Insight in the Recent Application of Polyphenols From Biomass. Front. Bioeng. Biotechnol 9, 753898. doi:10.3389/fbioe.2021.753898

Yang, J., Si, C., Liu, K., Liu, H., Li, X., Liang, M., et al. (2020). Production of Levulinic Acid from Lignocellulosic Biomass and Application. J. Forest. Eng. 5 (5), 21-27. doi:10.13360/j.issn.2096-1359.201905013

Yang, X., Xie, H., Du, H., Zhang, X., Zou, Z., Zou, Y., et al. (2019). Facile Extraction of Thermally Stable and Dispersible Cellulose Nanocrystals with High Yield via a green and Recyclable $\mathrm{FeCl}_{3}$-Catalyzed Deep Eutectic Solvent System. ACS Sustain. Chem. Eng. 7, 7200-7208. doi:10.1021/acssuschemeng.9b00209

Yu, J.-X., Wang, L.-Y., Chi, R.-A., Zhang, Y.-F., Xu, Z.-G., and Guo, J. (2013). Competitive Adsorption of $\mathrm{Pb}^{2+}$ and $\mathrm{Cd}^{2+}$ on Magnetic Modified Sugarcane
Bagasse Prepared by Two Simple Steps. Appl. Surf. Sci. 268, 163-170. doi:10.1016/j.apsusc.2012.12.047

Zhang, G., Qu, J., Liu, H., Cooper, A. T., and Wu, R. (2007). $\mathrm{CuFe}_{2} \mathrm{O}_{4} /$ activated Carbon Composite: A Novel Magnetic Adsorbent for the Removal of Acid orange II and Catalytic Regeneration. Chemosphere 68, 1058-1066. doi:10.1016/j.chemosphere.2007.01.081

Zhang, H., Xue, G., Chen, H., and Li, X. (2018). Magnetic Biochar Catalyst Derived from Biological Sludge and Ferric Sludge Using Hydrothermal Carbonization: Preparation, Characterization and its Circulation in Fenton Process for Dyeing Wastewater Treatment. Chemosphere 191, 64-71. doi:10.1016/ j.chemosphere.2017.10.026

Zhang, L., Guo, J., Huang, X., Wang, W., Sun, P., Li, Y., et al. (2019). Functionalized Biochar-Supported Magnetic $\mathrm{MnFe}_{2} \mathrm{O}_{4}$ Nanocomposite for the Removal of $\mathrm{Pb}(\mathrm{ii})$ and $\mathrm{Cd}(\mathrm{ii})$. RSC Adv. 9, 365-376. doi:10.1039/ c8ra09061k

Zhang, M., Du, H., Liu, K., Nie, S., Xu, T., Zhang, X., et al. (2021). Fabrication and Applications of Cellulose-Based Nanogenerators. Adv. Compos. Hybrid. Mater. doi:10.1007/s42114-021-00312-2

Zhang, M., and Gao, B. (2013). Removal of Arsenic, Methylene Blue, and Phosphate by biochar/AlOOH Nanocomposite. Chem. Eng. J. 226, 286-292. doi:10.1016/j.cej.2013.04.077

Zhu, S., Huang, X., Wang, D., Wang, L., and Ma, F. (2018a). Enhanced Hexavalent Chromium Removal Performance and Stabilization by Magnetic Iron Nanoparticles Assisted Biochar in Aqueous Solution: Mechanisms and Application Potential. Chemosphere 207, 50-59. doi:10.1016/ j.chemosphere.2018.05.046

Zhu, Y., Zheng, C., Wu, S., Song, Y., and Hu, B. (2018b). Interaction of Eu(III) on Magnetic Biochar Investigated by Batch, Spectroscopic and Modeling Techniques. J. Radioanal. Nucl. Chem. 316, 1337-1346. doi:10.1007/s10967-018-5839-8

Conflict of Interest: The authors declare that the research was conducted in the absence of any commercial or financial relationships that could be construed as a potential conflict of interest.

Publisher's Note: All claims expressed in this article are solely those of the authors and do not necessarily represent those of their affiliated organizations, or those of the publisher, the editors and the reviewers. Any product that may be evaluated in this article, or claim that may be made by its manufacturer, is not guaranteed or endorsed by the publisher.

Copyright (c) 2021 Zhao, Xu, Song, Nie, Choi and Si. This is an open-access article distributed under the terms of the Creative Commons Attribution License (CC BY). The use, distribution or reproduction in other forums is permitted, provided the original author(s) and the copyright owner(s) are credited and that the original publication in this journal is cited, in accordance with accepted academic practice. No use, distribution or reproduction is permitted which does not comply with these terms. 